\title{
PERANCANGAN AUGMENTED REALITY RUMAH ADAT SULAWESI SELATAN
}

\author{
Nira Caprisa ${ }^{1}$, Irfan $^{2}$ \\ ${ }^{12}$ Desain Komunikasi Visual Fakultas Seni dan Desain Universitas Negeri makassar \\ Coresponding Author: ncaprisa@gmail.com
}

\begin{abstract}
ABSTRAK
Perancangan ini bertujuan menciptakan sebuah media edukasi 3D dalam bentuk aplikasi Augmented Reality yang dapat menarik minat anak untuk mempelajari tentang rumah adat di Sulawesi Selatan. Kumpulan data dalam perancangan diperoleh melalui observasi, studi pustaka, wawancara/survey pada anak, dan wawancara kepada dinas kebudayaan. Konsep desain dalam perancangan augmented reality rumah adat Sulawesi Selatan adalah konsep ceria dengan komposisi desain, layout, dan warna yang sesuai dengan target audiens. Hasil perancangan ini adalah aplikasi augmented reality rumah adat Sulawesi Selatan beserta marker rumah adat tersebut pada buku pendamping. Perancangan ini juga berfungsi sebagai media edukasi atau pembelajaran bagi guru terhadap anak didik maupun orang tua terhadap anak.
\end{abstract}

Kata Kunci: Rumah Adat; Aplikas; Augmented Reality; Edukasi 3D

\section{ABSTRACT}

This design aims to create a 3D educational media in the form of Augmented Reality applications that can attract children to learn about traditional houses in South Sulawesi. Collection of data in the design obtained through observation, literature study, interviews / surveys of children, and interviews with the department of culture. The design concept in the design of augmented reality South Sulawesi traditional house is a cheerful/fun concept with the composition of design, layout, and color that suits the target audience. The results of this design are augmented reality applications of South Sulawesi traditional house along with the marker of the traditional house in the companion book. This design also functions as a media of education or learning media for teachers of students and parents of children.

Keywords: Traditional House, Application, Augmented Reality, 3D Education

\section{PENDAHULUAN}

Indonesia merupakan negara

kepulauan yang mencakup lebih dari 17.000 pulau yang dihuni oleh sekitar 255 juta penduduk, sebuah angka yang membuat Indonesia menjadi negara di urutan keempat dengan jumlah populasi terbesar di dunia. Angka ini juga mengimplikasikan bahwa banyak keanekaragaman budaya, etnis, agama maupun linguistik yang dapat ditemukan di dalam negara ini.

Saat ini, minat orang Indonesia untuk mempelajari budaya mereka sendiri diduga semakin menurun. Selain itu, hasil kebudayaan tradisional diperhadapkan pada suatu kenyataan yang sulit untuk dielakkan oleh adanya interaksi budaya global yang membawa sejumlah perubahan. Perubahan yang tidak hanya terbatas pada permukaan, tetapi lebih jauh, sampai kepada perubahan struktural dan substansial yang dapat berdampak pada terpinggirkannya kearifan lokal yang terkandung di dalamnya. Kemajuan teknologi sebagai ciri dari pengaruh global memang tidak dapat diabaikan, namun untuk hanyut sepenuhnya dalam teknologi dan mengorbankan kebudayaan sebagai hakikat dari jati diri bangsa, juga kurang arif. (Saing, 2010:5). 
Dengan adanya keanekaragaman suku, bangsa dan budaya di Indonesia ini tidak sepenuhnya didukung oleh media informasi tentang kebudayaan yang menyajikan pengetahuan kepada masyarakat sesuatu yang menarik dan baru. Kebanyakan dari buku sejarah \& kebudayaan identik dengan sesuatu yang membosankan dan kuno sehingga minat rasa ingin tahu menjadi semakin menurun.

Budayawan Jose Rizal Manua menjelaskan, budaya asing, khususnya dari barat, berhasil mempengaruhi pelajar Indonesia. Di era pendidikan saat ini, anakanak Indonesia banyak yang masih buta terhadap budaya karena pengaruh globalisasi yang mempengaruhi jaman. Pembelajaran seni budaya sangat berperan penting untuk mengasah pengetahuan dan keterampilan siswa, menurut buku guru Kemendikbud 2013. Untuk membentengi perkembangan budaya luar, pendidikan seni dan budaya sejak usia dini wajib diberikan kepada setiap pelajar. Ketika observasi awal, dilakukan survey pada anak usia 7-12 tahun di SDN Kompleks Mangkura. Fenomena yang terjadi, siswa kurang antusias terhadap materi seni budaya dan cenderung malas ketika materi yang diajarkan adalah tentang rumah-rumah adat, mereka beranggapan bahwa belajar tentang rumah adat membosankan. Pembelajaran materi rumah adat meliputi pemahaman siswa tentang rumah rumah adat yang berada di Indonesia. Hal tersebut bertujuan untuk membangun nilai-nilai moral dan karakter bangsa yang bermanfaat bagi mereka. Namun kenyataannya anak-anak kurang tertarik dengan materi yang diajarkan yaitu seni budaya tentang rumah adat. Untuk itu perlu inovasi media tentang pembelajaran rumah adat agar siswa dapat mencintai dan melestarikan kebudayaan bangsa. Dengan adanya media pembelajaran, maka proses pembelajaran akan lebih menarik perhatian peserta didik, sehingga dapat menumbuhkan motivasi belajar bagi peserta didik. Motivasi yang tinggi pada peserta didik akan membuat peserta didik lebih semangat dalam belajar, sehingga diharapkan hasil belajar peserta didik juga akan meningkat. (Sudjana N, 1992:62).

Sebagai penerus generasi dan pewaris budaya bangsa, siswa diharapkan dapat melestarikan budaya bangsa di era globalisasi ini, tanggapan dan respon siswa terhadap materi pembelajaran rumah adat menjadi permasalahan yang cukup serius. Saat ini, dunia menjelma menjadi era digital/cyberworld, yaitu budaya komunikasi secara online dan koneksitas secara virtual (semu atau maya). Pengaruh media digital terhadap anak dan orang dewasa semakin besar karena teknologi semakin canggih dan intensitasnya semakin tinggi. (Wulansari, 2017:2).

Oleh karena itu, dalam kesempatan kali ini penulis akan melakukan penelitian atau studi pengetahuan tentang budaya yang di Sulawesi Selatan terkhusus pada "RumahRumah Adat di Sulawesi Selatan" dalam bentuk media edukasi 3D untuk menarik minat anak anak dalam mengetahui dan mempelajarinya. Gambar pada dasarnya membantu mendorong para siswa dan dapat membangkitkan minatnya pada pelajaran. Membantu mereka dalam kemampuan berbahasa, kegiatan seni, dan pernyataan kreatif dalam bercerita, dramatisasi, bacaan, penulisan, melukis dan menggambar serta membantu mereka menafsirkan dan mengingat-ingat isi materi bacaan dari buku teks. (Sadiman, 1984:28).

Penelitian ini dilakukan untuk merancang media pembelajaran tentang budaya, khususnya rumah adat Sulawesi Selatan dengan media 3D untuk membantu anak anak di Sulawesi Selatan dalam mempelajari budaya tentang rumah adat Sulawesi Selatan. Tampilan interaktif memungkinkan anak-anak tertarik untuk mempelajari dan memperoleh informasi dengan media bergambar. Dengan penelitian ini, anak-anak dapat dibantu untuk belajar dan memperoleh informasi budaya tentang rumah adat Sulawesi Selatan dengan media interaktif sebagai salah satu bentuk media pembelajaran.

Kebudayaan merupakan salah satu aset suatu bangsa yang patut untuk dijaga dan dilestarikan, serta diberikan secara turun temurun yang bertujuan agar kebudayaan suatu bangsa tersebut tidak hilang ditelan zaman modern yang semakin hari semakin berkembang. Dengan tetap melestarikan kebudayaan bangsa maka kita juga ikut serta dalam menjaga identitas atau ciri khas dari suatu bangsa itu sendiri. 


\section{METODE PENELITIAN}

Metode yang digunakan dalam proses pengumpulan dan analisis data ialah, Teknik Pengumpulan data dengan kajian kepustakaan. Pada tahap ini dilakukan studi kepustakaan terhadap berbagai referensi berdasarkan kata kunci perancangan yang akan dibuat. Dengan mengumpulkan data dari bukubuku, jurnal, atau internet. Data yang diperoleh ini akan menjadi data sekunder yang akan mendukung data hasil survey. Materi-materi yang menjadi kata kunci dalam mencari referensi adalah sebagai berikut, rumah tradisional, rumah tradisional Sulawesi Selatan, kebudayaan, desain, dan teori-teori lain yang mendukung. Studi kepustakaan dilakukan pada bulan april 2019.

Pada tahap ini, dilakukan juga proses wawancara dengan beberapa murid-murid di SDN Mangkura III, dan juga wawancara dengan anak-anak di lingkungan tempat tinggal penulis, yang berusia kisaran 7-12 tahun. Adapun daftar pertanyaan dalam wawancara tersebut adalah sebagai berikut:

1. Nama respoden

2. Usia Responden

3. Asal sekolah responden

4. Tingkatan kelas responden

5. Apakah responden sudah belajar tentang seni budaya disekolah?

6. Jika sudah, apakah responden diajarkan tentang rumah-rumah

7. adat di Sulwesi Selatan?

8. Rumah-rumah adat apa saja yang responden ketahui di Sulawesi Selatan? Dalam menganalisis data, penulis menggunakan pendekatan kualitatif, dengan metode penelitian wawancara/survey yang dilakukan bersama anak usia 7-12 tahun. Adapun hasil analisis yang didapatkan yaitu:

1. Materi komunikasi yang akan disampaikan yaitu memperkenalkan rumah-rumah adat Sulawesi Selatan.

2. Target audiens dalam perancangan ini adalah anak usia 7-12 tahun.

3. Perencanaan media yang diusulkan penulis adalah membuat media edukasi 3D Augmented Reality rumah-rumah adat di Sulawesi Selatan yang komunikatif dan membawa konsep baru dalam pembelajaran. Selain itu media edukasi ini diharapkan dapat meningkatkan minat dan ketertarikan anak untuk mempelajari budaya. Ada beberapa media yang menjadi pilihan penulis dalam perancangan ini yaitu buku Augmented Reality, Pop Up Book, dan buku ilustrasi. Dalam perancangan ini penulis memilih media Augmented Reality dengan metode analisis SWOT berikut:

a. Strength (kekuatan) Perancangan media

Augmented Reality rumah adat di Sulawesi Selatan memiliki kekuatan pada pemilihan topik dan visualisasi dari media 3D yang akan dirancang. Kelebihannya juga karena efisien dan lebih dapat mendorong motivasi belajar karena Augmented Reality memasukkan konten visual grafis 3D yang menarik. Ditambah, belum ada yang membuat media ini dengan lengkap karena berdasarkan observasi penulis, belum ada yang membuat media edukasi rumah-rumah adat yang terdapat di Sulawesi Selatan yang lebih merinci. Kebanyakan hanya membuat rumah yang terkenal saja seperti rumah Tongkonan dan Balla Lompoa. Kemudian karena sifatnya yang praktis, di jaman modern seperdi sekarang ini sangat mudah mengakses teknologi dimanapun hanya dengan cara mendapatkan aplikasinya terlebih dahulu. Lalu kelebihannya juga adanya interaksi yang dibangun bersama orang tua karena orang tua ikut berperan aktif untuk mengawasi dan memberi bimbingan kepada anak untuk menggunakan teknologi ini. Seperti yang diketahui Augmented Reality menggunakan handphone sebagai media untuk melihat gambar 3D dari edukasi ini. Orang tua berperan penting untuk memberi batasan kepada anak dalam menggunakan teknologi.

b. Weakness (Kelemahan) Perancangan Augmented

Reality rumah adat di Sulawesi Selatan ini memiliki kelemahan yaitu butuh pengawasan dan peran orang tua untuk membatasi penggunaan handphone, meskipun anak-anak sudah dapat mengaksesnya sendiri 
mengingat perkembangan jaman yang pesat seperti sekarang ini.

c. Opportunity (Peluang)

Peluang yang didapatkan dari Augmented Reality rumah adat di Sulawesi Selatan sangat besar, karena merupakan inovasi dari pembelajaran yang membosankan dan hanya begitubegitu saja. Dapat memberikan motivasi belajar yang besar kepada anak karena media yang baru dan inovatif.

d. Threat (Ancaman)

Ancaman yang akan dihadapi perancangan Augmented Reality rumah adat di Sulawesi Selatan adalah banyaknya edukasi di internet tentang rumah adat di Sulawesi Selatan yang dapat dilihat dan mudah diakses juga.

\section{HASIL DAN PEMBAHASAN}

\section{Konsep Desain}

Pada perancangan aplikasi Augmented Reality rumah-rumah adat di Sulawesi Selatan ini, akan mengusung konsep fun atau ceria dan menyenangkan dengan mempertimbangkan target audiensnya yaitu anak usia 7-12 tahun. Desain yang akan dibuat adalah tampilan visual pada aplikasi dengan menggunakan gaya desain yang simpel dan mudah dipahami oleh anak-anak. Perancangan media Augmented Reality rumah adat di Sulawesi Selatan ini memasukkan konten visual grafis 3D dengan cara memindai marker pada buku yang akan berfungsi sebagai panduan. Buku ini berisi tentang rangkuman dan pengetahuan singkat rumah-rumah adat di Sulawesi Selatan serta marker-marker rumah adat agar tampilan 3D dapat dilihat melalui aplikasi Augmented Reality yang sudah diunduh pada smartphone. Mengusung konsep desain ceria, Augmented Reality rumah-rumah adat di Sulawesi Selatan ini dibuat menggunakan warna cerah untuk memberikan kesan ceria.

\section{Media Utama}

Augmented Reality

Hasil perancangan ini menggunakan aplikasi Blender 2.8, Unity 2018.4.7, Android Studio, Visual Studio 2019 dan Vuforia. Untuk membuat visualiasi 3D, menggunakan aplikasi blender 2.8 dari rumah adat Tongkonan, Sao Mario, Saoraja La Tenri Bali, Saoraja Lapinceng, Bola Soba, dan Balla Lompoa. Kemudian visualiasi tersebut di input ke aplikasi Unity 2018.4.7 untuk mengatur rumah adat tepat berada di atas marker yang telah dibuat. Serta membuat tampilan aplikasi juga dan memasukkan button- button yang telah dirancang sebelumnya. Selanjutnya aplikasi di build dan menghasilkan output berupa aplikasi Android (apk) dengan ukuran aplikasi 70,4 $\mathrm{Mb}$, serta dapat dioperasikan pada smartphone android minimal sistem operasi Jelly Bean 4.3 dan smartphone yang memiliki fitur kamera.

Untuk dapat melihat tampilan 3D dari rumah-rumah adat, pengguna harus memindai atau melakukan scan pada marker yang ada di buku pendamping. Dengan cara membuka terlebih dulu aplikasi, kemudian memilih menu scan pada menu utama. Lalu menggerakkan kamera tepat di atas marker.

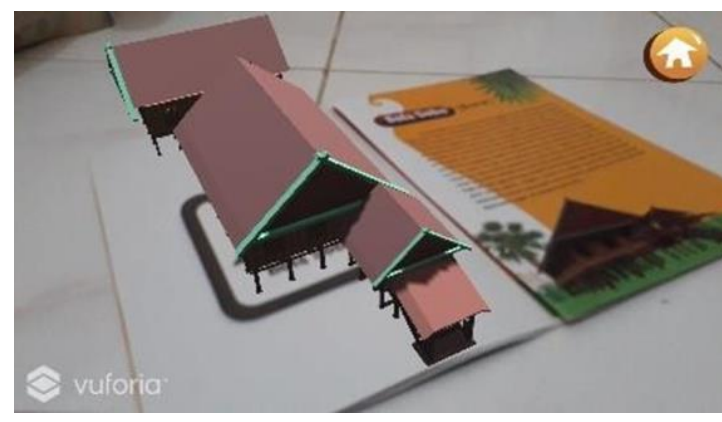

Gambar 1. AR rumah adat Bola Soba (Sumber: Nira Caprisa, 2019)

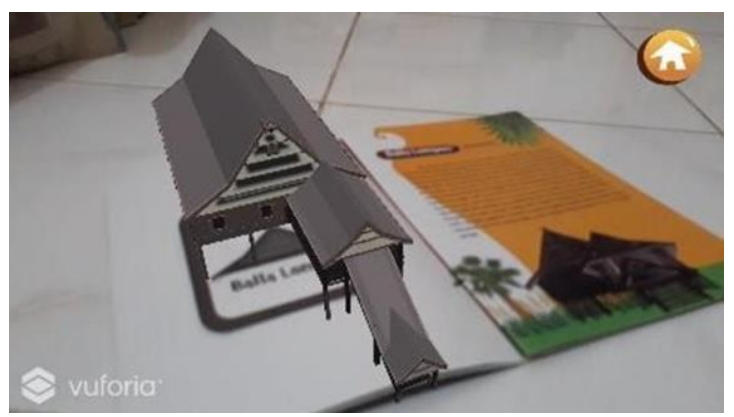

Gambar 2. AR rumah adat Balla Lompoa (Sumber: Nira Caprisa, 2019) 


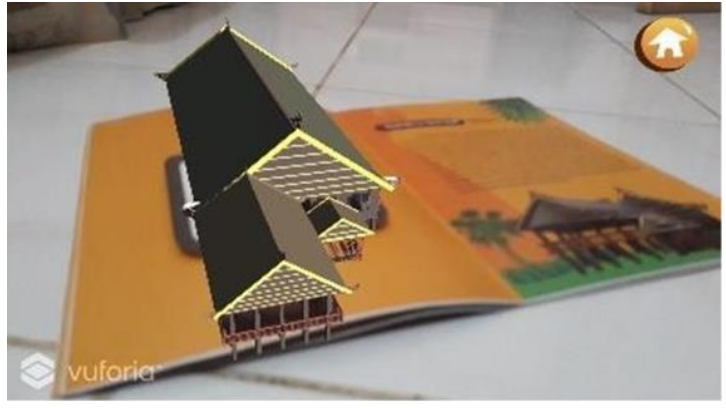

Gambar 3. AR rumah adat Saoraja La Tenri Bali (Sumber: Nira Caprisa, 2019)

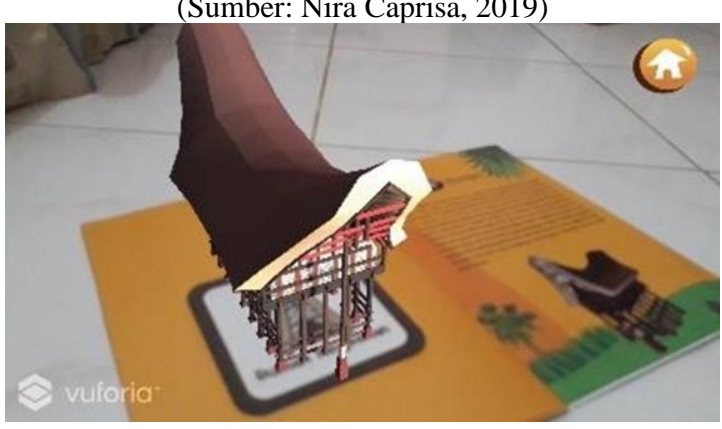

Gambar 4. AR rumah adat Tongkonan (Sumber: Nira Caprisa, 2019)

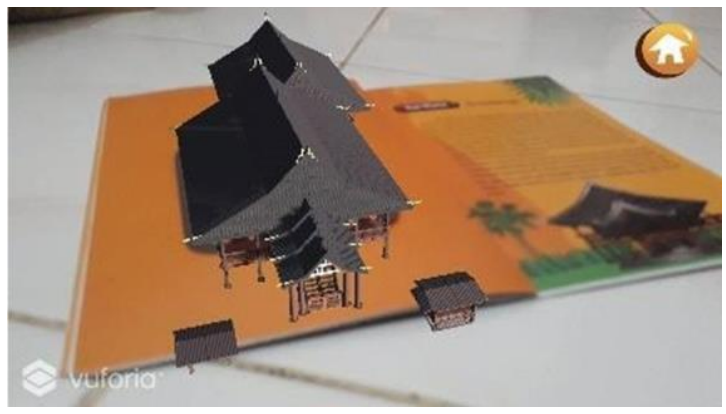

Gambar 5. AR rumah adat Sao Mario (Sumber: Nira Caprisa, 2019)

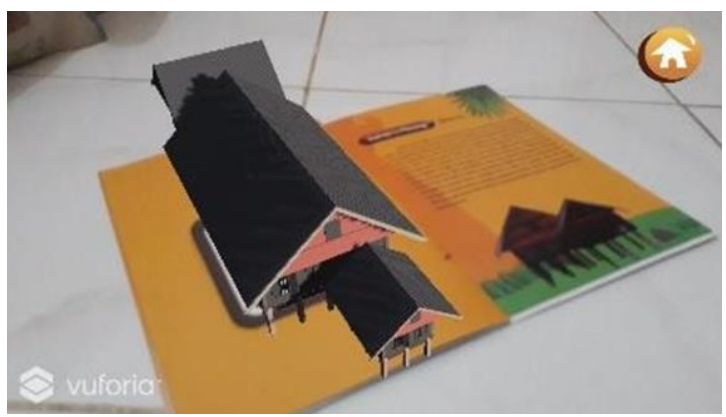

Gambar 6. AR rumah adat Saoraja La Pinceng (Sumber: Nira Caprisa, 2019)

\section{Media Pendukung \\ Buku Pendamping}

Buku Pendamping merupakan media pendukung yang berisi marker dari rumah adat Tongkonan, Sao Mario, Saoraja La Tenri Bali, Saoraja Lapinceng, Bola Soba, dan Balla Lompoa. Marker ini dapat di scan dan menghasilkan visualisasi 3D dari ke enam rumah adat tersebut.

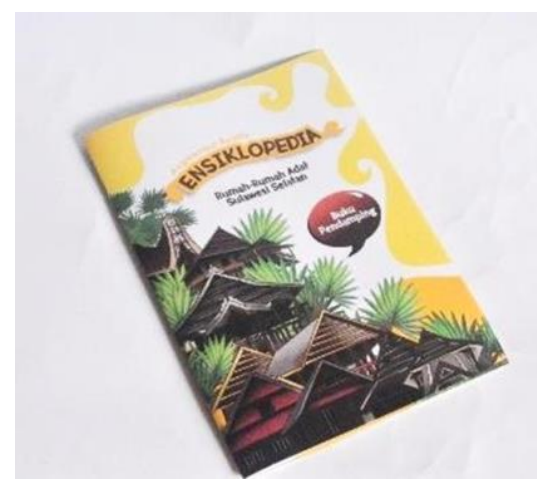

Gambar 3.7. Buku Pendamping (Sumber: Nira Caprisa, 2019)

\section{Banner}

$\mathrm{X}$ banner Digunakan sebagai media pendukung untuk menginformasikan secara singkat tentang aplikasi yang dibuat agar audience tertarik.

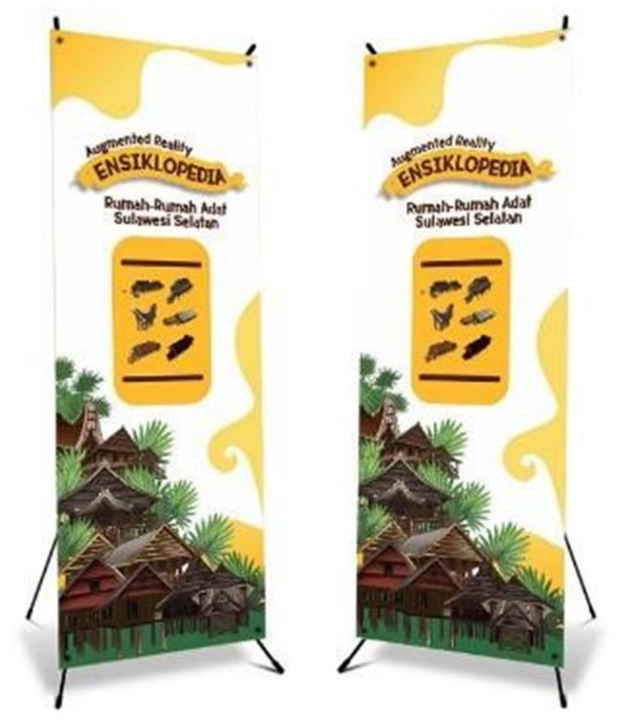

Gambar 3.8. X Banner (Sumber: Nira Caprisa, 2019) 
Stiker

Stiker berisi marker serta link untuk mengunduh aplikasi, serta diharapkan dapat menjadi media promosi augmented reality rumah-rumah adat di Sulawesi Selatan.

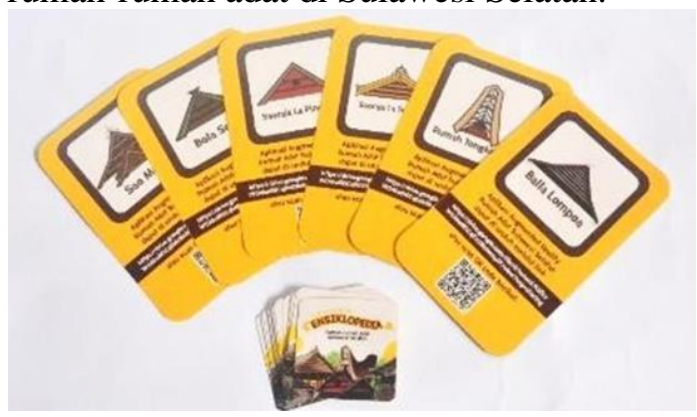

Gambar 3.9. Stiker

(Sumber: Nira Caprisa, 2019)

Poster

Poster berfungsi sebagai media pendukung untuk mengajak target audiens merasakan pengalaman melihat rumah adat langsung dengan cara mengunjungi museum/dating langsung ke tempat rumah adat tersebut dengan didampingi oleh orang tua tentunya.

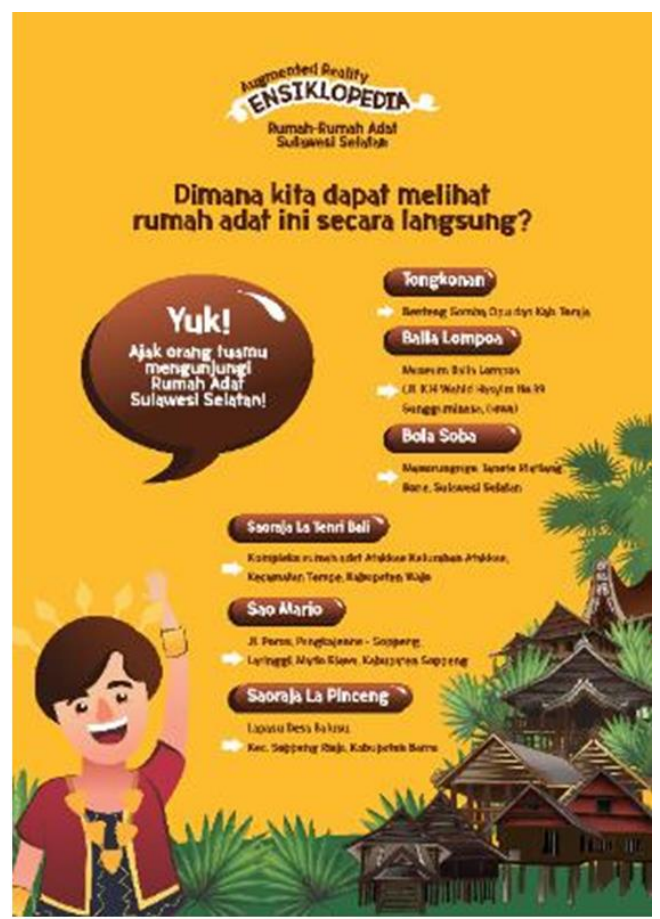

Gambar 3.10. Stiker (Sumber: Nira Caprisa, 2019)

\section{Merchandise}

\section{Gantungan Kunci}

Gantungan kunci yang diproduksi dengan teknik cetak digital printing dapat menjadi media promosi sekaligus media pengenalan augmented reality rumah- rumah adat di Sulawesi Selatan. Gantungan kunci ini bergambar 6 rumah adat yang telah dibuat model 3D nya yaitu Tongkonan, Sao Mario, Saoraja La Tenri Bali, Saoraja Lapinceng, Bola Soba, dan Balla Lompoa

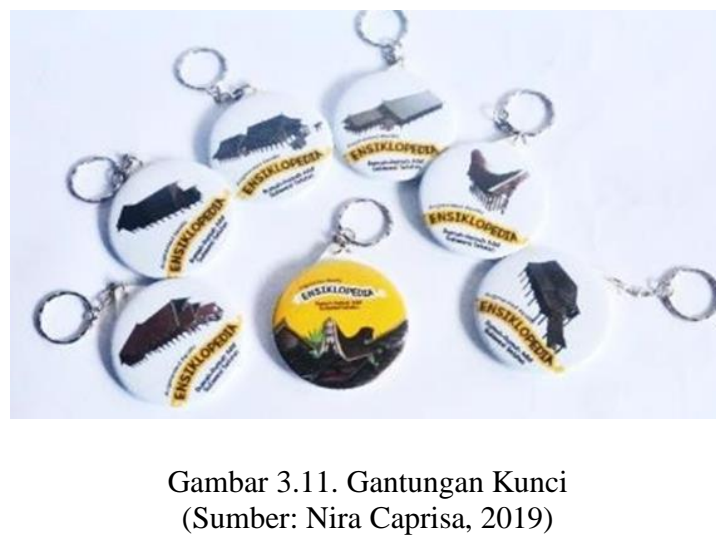

Ransel Mini

Ransel Mini dengan bahan polyester dan dicetak sbalon ini diharapkan dapat menjadi media promosi augmented reality rumah-rumah adat di Sulawesi Selatan.
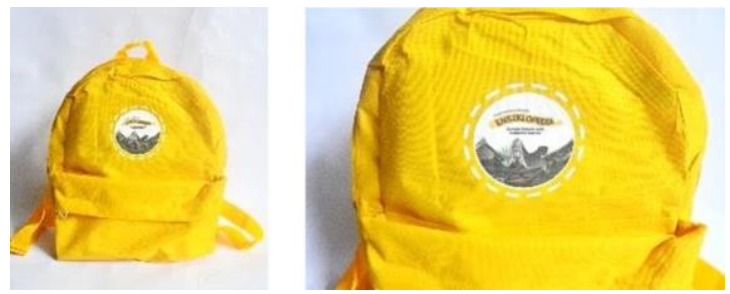

Gambar 3.12. Ransel Mini

(Sumber: Nira Caprisa, 2019)

Mug

Mug dengan bahan keramik dan dicetak sbalon ini diharapkan dapat menjadi media promosi augmented reality rumahrumah adat di Sulawesi Selatan 


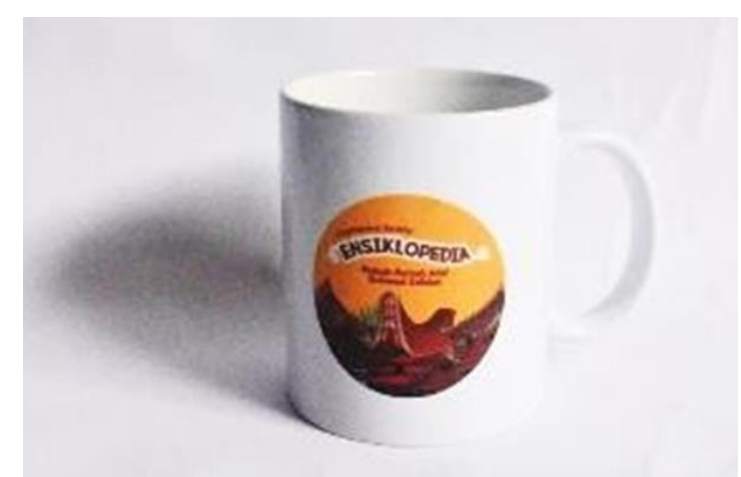

Gambar 3.13. Mug

(Sumber: Nira Caprisa, 2019)

Tempat Pensil

Tempat pensil dengan bahan polyester dan dicetak sablon ini diharapkan dapat menjadi media promosi augmented reality rumah-rumah adat di Sulawesi Selatan.

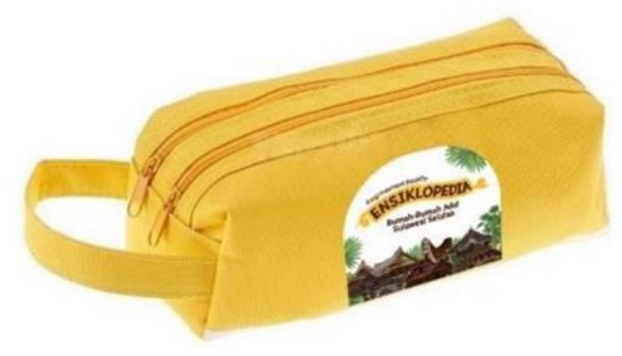

Gambar 3.14. Tempat Pensil (Sumber: Nira Caprisa, 2019)

\section{SIMPULAN DAN SARAN}

Augmented Reality dibuat dengan aplikasi Blender 2.8, Unity 2018.4.7, Android Studio, Visual Studio 2019 dan Vuforia yang menghasilkan output berupa aplikasi Android (apk) dengan ukuran aplikasi 70,4 Mb, serta dapat dioperasikan pada smartphone android minimal sistem operasi Jelly Bean 4.3 dan smartphone yang memiliki fitur kamera.

Untuk dapat melihat tampilan 3D dari rumah-rumah adat, pengguna harus memindai atau melakukan scan pada marker yang ada di buku pendamping. Dengan cara membuka terlebih dulu aplikasi, kemudian memilih menu scan pada menu utama. Lalu menggerakkan kamera tepat di atas marker.

Perancangan ini merupakan media pembelajaran tentang budaya, khususnya rumah adat Sulawesi Selatan dengan media 3D yaitu Augmented Reality untuk membantu anak anak di Sulawesi Selatan dalam mempelajari budaya rumah adat Sulawesi Selatan. Tampilan yang menarik dan interaktif memungkinkan anak-anak tertarik untuk mempelajari dan memperoleh informasi dengan media ini. Tidak hanya sebatas itu, perancangan ini diharapkan dapat menjadi media promosi tentang Sulawesi Selatan.

Perancangan Augmented Reality Rumah Rumah Adat Sulawesi Selatan masih memiliki banyak kekurangan karena keterbatasan yang dimiliki penulis. Oleh karena itu, perlu dikembangkan dan disempurnakan lebih lanjut. Terlepas dari keterbatasan yang dimiliki, hasil perancangan ini diharapkan dapat memberikan manfaat dan kontribusi untuk penelitian selanjutnya dengan topik serupa. Adapun beberapa saran yang dimiliki penulis sebagai berikut:

1. Agar pesan dari perancangan Augmented Reality Rumah Rumah Adat Sulawesi Selatan mudah dipahami oleh anak anak, sebaiknya pada saat anak menyaksikan video didampingi oleh orang tua, agar anak mendapatkan penjelasan serta makna dari rumah-rumah adat tersebut.

2. Untuk mengembangkan aplikasi Augmented Reality Rumah Rumah Adat Sulawesi Selatan, diharapkan untuk memperhatikan target audiens yang dituju.

3. Bagi perancangan dengan topik serupa diharapkan dapat berkolaborasi dengan budayawan atau ahli agar dapat menghasilkan perancangan yang lebih baik lagi.

\section{DAFTAR PUSTAKA}

Boud, A. C. (1999). Virtual reality and augmented reality as a training tool for assembly tasks.

Data, D. M., T, L. T., Yuniar, H., Mappasere, \& Rusdy, R. (1985). Arsitektur Tradisional Daerah Sulawesi Selatan. Makassar: Balai Kajian Sejarah dan Nilai Tradisional Ujung Pandang.

Janottama, I. P., \& Putraka, A. N. (2017). Gaya dan Teknik Perancangan Ilustrasi Tokoh 
pada Cerita Rakyat Bali. SEGARA WIDYA Jurnal Hasil Penelitian, 28.

Koentjaraningrat. (1983). Kebudayaan Mentalitas dan Pembangunan. Jakarta: PT Gramedia.

Kusrini, M., \& Koniyo, A. (2007). Tuntunan Praktis Membangun Sistem Informasi Akuntansi dengan Visual Basic

dan Microsoft SQL Server. Andi

Publisher.

Ladjamuddin, A.-B. b. (2005). Analisis dan Desain Sistem Informasi. Yogyakarta: Graha Ilmu.

Milgram. (1994). Augmented Reality: A Class of Displays on the Reality-Virtuality Continuum.

Nehan. (2018, july 18). Rumah Adat Bugis Di Berbagai Daerah. Retrieved from nehanesia: https://nehanesia.com/rumahadat-bugis/

Pakerti, B. A. (2017). 3. Pengembangan Aplikasi Augmented Reality untuk Meningkatkan Hasil Belajar Siswa Smp Negeri 2 Banyumas Pada Mata Pelajaran Ipa Tata Surya.

Pengertian Kebudayaan. (2012, oktober

8). Retrieved from Budaya Indonesia Bhineka tunggal ika: https://www.ejurnal.com/2013/10/pengertian-

kebudayaan.html Budaya Indonesia Bhinekka Tunggal Ika | Indonesia Investments www.indonesiainvestments.com

Prabowo, R., Listyorini, T., \& Jazuli, A. (2015). Pengenalan Rumah Adat Indonesia Berbasis Augmented Reality dengan memanfaatkan KTP sebagai Marker. Prosiding SNATIF.

Sachari, A. (2005). Pengantar Metodologi Penelitian Budaya Rupa: Desain, Arsitektur, Seni Rupa dan Kriya. Jakarta: Erlangga.

Sadiman, A. S. (1984). Media Pendidikan Pengembangan dan Manfaat. Jakarta: PT Raja Grafindo.

Safanayong, Y. (2006). Desain Komunikasi Visual Terpadu. Jakarta Barat: Arte Intermedia.

Said, A. A. (2004). Toraja: Simbolisme Unsur Visual Rumah Tradisional. Yogyakarta: Ombak.

Said, A. A. (2006). Dasar Desain Dwimatra. Makassar: Penerbit UNM Makassar.
Saing, A. (2010). Arsitektur Tradisional Rumah Adat Bugis Makassar. Makassar: Indhira Art.

Satrioadi, R. B. (2014). Pengenalan Budaya Papua dengan Augmented Reality Berbasis Android.

Sudjana N, A. R. (1992). Media Pengajaran. Bandung: Sinar Baru Algensindo.

Wulansari, N. M. (2017). Didiklah Anak Sesuai Zamannya. Jakarta Selatan: PT Visimedia Pustaka. 